\title{
A visual method based on Lewis dot electron structures (VISLEDS) for teaching inorganic formulation
}

\author{
Abigail Jiménez ${ }^{1}$ \\ ${ }^{1}$ I. E. S. Luis de Camoens, Ceuta (Spain)
}

\begin{abstract}
Chemistry is usually seen as a difficult subject for secondary school students. One topic they struggle is when they face chemistry formulation for the first time. The concept of oxidation number is difficult for them. The level of abstraction required is still developing in their minds. We must help them visualise it, to understand bonding and, finally, the symbolic representation of chemical compounds.
\end{abstract}

We find in chemistry a visual description for bond formation: Lewis diagrams. They explicitly show molecular bonds as paired electrons. By using this simple idea, we can introduce formulation to secondary school students. Starting with binary chemical compounds, included in $3^{\text {rd }}$ year of secondary schools in Spain, we can set up the foundations for their future chemistry studies. Of course, the difficulty must be progressively introduced.

In this work, we show how a visual method based on Lewis diagrams improves the performance of students when writing formulae of binary chemical compounds. One important difference with current literature on how Lewis dot structures are used in education, is that, while they are usually presented as a learning goal, here we use them as a means to an end.

Our results suggest that the improvement is higher for students with previous lower academic performance, low scores in linguistic competencies, and high scores in visual and artistic competencies. Most importantly, it does not worsen performance for students with high scores in linguistic competencies and low scores in visual and artistic competencies. Mathematical competencies do not seem to be so good predictors for students' performance.

Finally, within the Cognitive Load Theory framework, we show how cognitive working load, as well as an approximation of extraneous cognitive load, can be estimated by using information theory measures involving the mistakes students make. 
1. Introduction

It is well-known how difficult it is for secondary school students to face chemistry formulation for the first time [1]. Students must make sense of theories describing the invisible. They need to understand how matter is constituted at the molecular level, and usually have a problem with the concept of chemical bonds, particularly when referring to chemical formulae. Even if they are able to write the formula's compound, they would struggle when drawing or describing its bonds.

The current educational system in Spain is based on the theory of competency-based learning $[2,3]$. This conception is itself based on the constructivist theories $[4,5,6,7]$. They all propose that knowledge is constructed in the mind of the learner. In order to achieve useful learning and for it being transferrable, connections must be constructed between what is known and what is to be learned. They also emphasise that students have agency and may choose not to learn [8].



Figure 1. Johnstone's “Triplet” [9].

Chemistry teaching is mainly focused on problem-solving activities, as most scientific subjects are. Actually, is one of its main learning goals [8]. It has been shown that this particular capacity is different for novices and experts. The aim is to facilitate expert-like knowledge in students [10]. The paradigm in chemistry education is the Johnstone's "Triplet" [11], which illustrates how chemistry requires for experts to constantly switch between three 
"levels of thought", something a student, a non-trained learner, must be taught to (Figure 1). For a thorough review, see [8]. When new to chemistry formulation, none of these levels are connected or even developed. Not much previous knowledge is found yet. Thus the difficulty when teaching it. Johnstone, in his work, sought to illustrate the unreasonable cognitive demand imposed by chemistry instruction that focuses on all three thought levels simultaneously [8]. Experts are able to do just that, because they developed strategies to classify problems into categories, instead of using means-end analysis, which involves attempting to reduce differences between each problem state encountered and the goal state using the operators within the mathematical models available [12]. The means-end strategy involves a higher cognitive load.

Within the Cognitive Load Theory [13, 14], the acquisition of knowledge appears to be heavily reliant on two factors: the degree of complexity of the new information to be processed, and the way in which that information is presented. This framework's central idea is the "total working memory load" as the "mental effort" or, simply, cognitive load. It represents the number of information elements that need to be processed simultaneously. The more working memory dedicated to dealing with the way information is presented, called extraneous cognitive load, the less memory is available for dealing with the intrinsic content of information, or intrinsic cognitive load [13].

It is common practice to use pictorial representations when teaching scientific subjects in low level grades. An advantage is their capability to present information in a more compact and cognitively efficient way, in which much of the needed information could be accessed at a single location without search [15]. Visual representations may therefore reduce the cognitive load imposed by intrinsically complex materials. We need to stablish a link between the visual, linguistic and mathematical (symbolic) representations in order for learners to acquire expert-like knowledge in chemistry.

While visual perception reflects the capacity to discern geometric forms, assigning a form to each object, language stablishes correlations between forms. We can describe our world as long as we can articulate it as a language. Mathematics, however, represents a higher level description, because is a method for logic, for language [16]. We represent propositions about objects in mathematical language. We then manipulate them and obtain other propositions referring to the same objects, to solve the problems. So, the hierarchy is first objects (forms, visual perception), then propositions between objects (language), and finally translation to a 
higher level language (mathematics), in order to manipulate those propositions by means of tautologies (Figure 2). Depending on the different competencies students have, they will capitalise from the different ways information is presented [17].

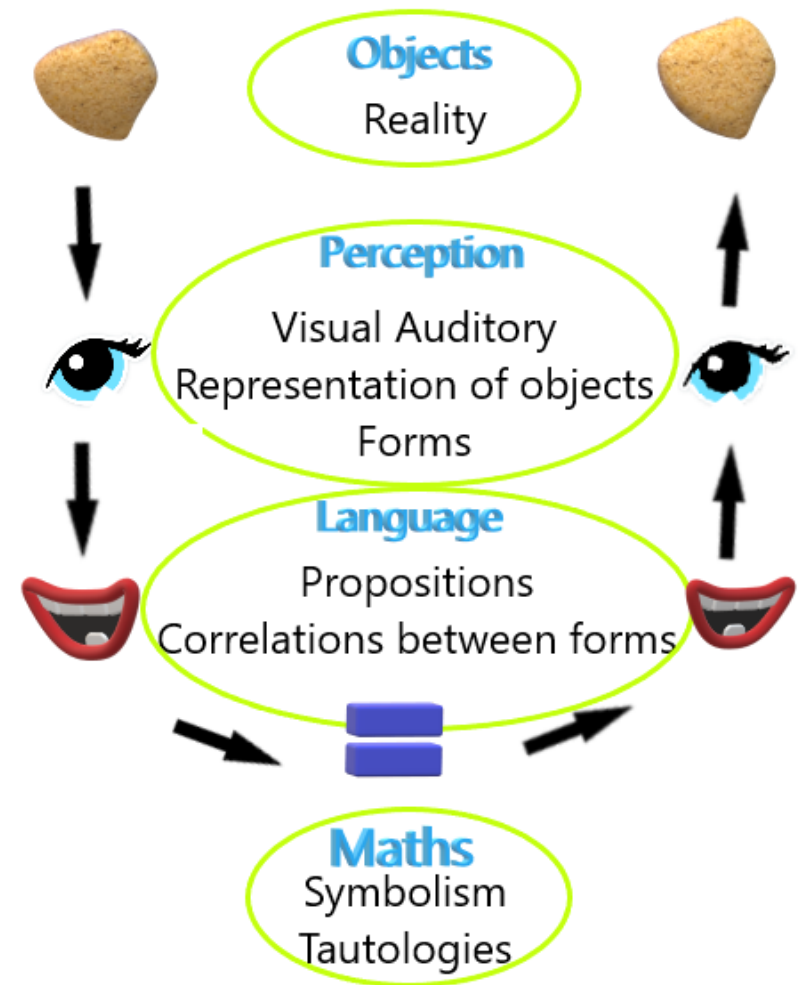

Figure 2. Levels of representations.

Inorganic formulation teaching, in terms of the Johnstone's "Triplet" [11], deals with the connection between the sub-micro and symbolic levels, one invisible and the other still highly abstract for $3^{\text {rd }}$ year students. This particular topic is usually taught by means of mnemonic rules. Students who are proficient in communication and mathematical competencies, do not usually have any problems to acquire the pertinent knowledge. However, this is not always the case. It has been found that difficulties in learning chemistry are related to low communicative competencies, low previous knowledge or low capacity for organizing and processing information [18]. Therefore, we must help them by presenting information in a compact way. On top of that, most of dropout students in Ceuta (Spain) presented low scores in the communication competency [19]. It means we will encounter this problem many times here.

Lewis dot structures [20] are the simplest visual representation of bonding between atoms. They have been used for teaching non-chemistry and chemistry majors in the literature [21, 22]. However, they are taught after students already know how to write formulae. Moreover, 
they are presented as sets of rules for drawing Lewis structures, which is not really the purpose of developing representational competence as a scientific tool [22].

In this study, we introduce a new method that utilises Lewis dot structures as visual representations of formulae. We use them as a tool to lower the cognitive load, to facilitate the learning for students who are new to chemical formulation, and not as the learning goal. Figure 3 shows how students can easily identify the relative quantities of the elements in a chemical compound when using Lewis dot structures.

\section{Li :O요 Li $\quad \mathrm{Li}_{2} \mathrm{O}$}

Figure 3. The Lewis dot diagram reflects the elements and their relative proportions in a formula.

We tested the method in a group with 24 students. We then proceeded to analyse the data obtained within the Information Theory framework [23, 24], and related those results to the Cognitive Load Theory $[13,14]$.

\section{Methods}

Here we detail the developed method, with learning objectives according to the syllabus for $3^{\text {rd }}$ grade in Secondary Schools in Spain [25]. That is, students must know how to write formulae and to name binary chemical compounds.

We also describe the different statistical analysis used to understand how this new method affects the way students learn, and if students improve their baseline chemistry knowledge.

2.1 A visual method based on Lewis dot electron structures (VISLEDS) for teaching inorganic formulation

In Figure 4 we show all the steps followed to teach, in a gradual way, inorganic formulation. Students are supposed to already know the basics of the atomic theory and the structure of atoms, as described by the Rutherford model [26].

We start defining chemical bonds as paired electrons between elements. We then proceed to familiarize students with the periodic table with different exercises and by drawing themselves their own periodic table. Writing helps learners to focus attention and optimize their cognitive load [27]. After that, we see how bonds can be schematically drawn by means 
of Lewis diagrams. We then correlate the oxidation numbers of elements with the available electrons to be paired as bonds. The remaining lectures are focused on the systematic formulation of the different binary compounds. To help knowledge acquisition, we gradually increase task complexity and decrease instructional support [13].

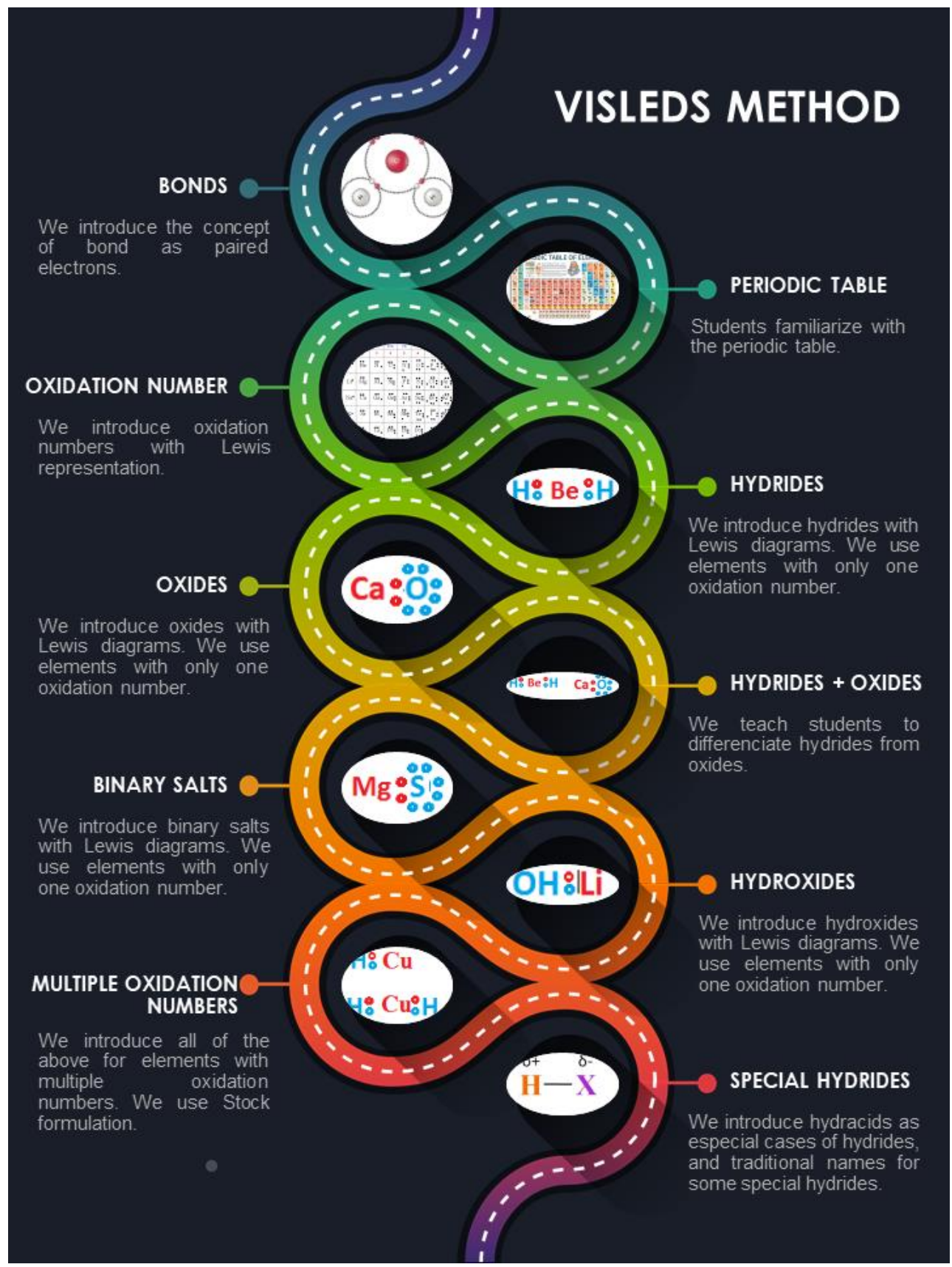

Figure 4. VISLEDS method.

A timeline of the different tests used to study the evolution of the learning process is illustrated in Figure 5. We include the initial exam where we stablish a baseline of previous knowledge on the relevant topics related to the one in hand. In particular, the questions related to the Rutherford model for the atom [26]. The process spans the whole first term. 
These tests have two purposes: first, to see the evolution of the performance of students over time, and second, to enhance retention [28].

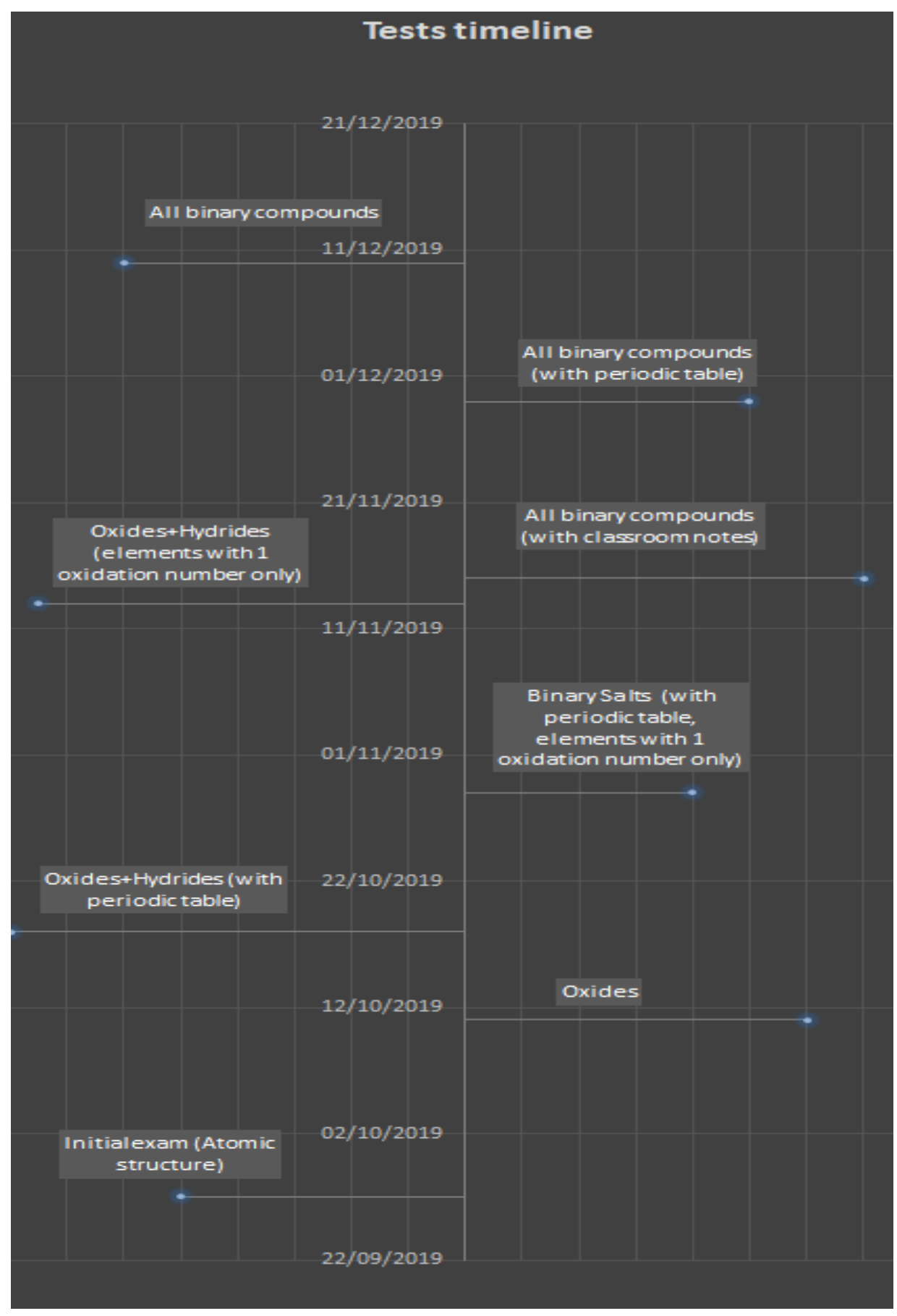

Figure 5. Tests' timeline.

2.2 Statistical analysis

All tests in Figure 5 had three different kind of questions. The first kind referred to writing formulae from the names of the chemical compounds. The second one, given a formula, 
students had to name it. Finally, the third kind required the association of Lewis dot structures to chemical formulae.

The statistical tools we use to analyse those data are varied. Box plots show the distribution of answers. We compare percentages of students who pass the initial exam to the percentage whom pass the final test as a measure of average improvement. It must be noted that in the first exam they had to surpass $1 / 2$ of total points, but for tests referred to formulation their overall mistakes had to be under $1 / 3$. That is our department's criterion.

We first analyse all data together. We proceed then to dividing the data into subgroups, according to different criteria, to a better understanding of the learning process. We investigate how their initial marks, the different levels on the linguistic, mathematical and artistic competencies, affect the results. Note that our current educational law [29] is based on the theory of competency-based learning $[2,3]$. It is interesting to see which competencies determine the acquisition of this particular knowledge. Which ones must be exploited and/or encouraged.

We also study how the performance on the different parts of the tests is correlated to the performance of students when describing formulae by their Lewis diagram, by means of the correlation coefficient [30] and the mutual information [31]. The mutual information represents the amount of information that one random variable has about another random variable, accounting for nonlinear correlations as well. This interpretation has been used in text analysis [32], computer vision [33], earthquakes [34], or psychology [35], for example. In the calculations, we divide the probability distributions into 10 intervals, because we found that this number of intervals satisfies the condition to find a robust estimator [36].

\section{Data}

The I.E.S. Luis de Camoens is a secondary school center located in Ceuta, Spain. Ceuta is considered a multicultural city, where Spanish might not be the student's mother tongue [37], and where we find one of the highest school dropout rates in Spain [19].

This study was made in a classroom with $243^{\text {rd }}$ year students, in which the syllabus is made of the following subjects (Table 1): 
Table 1. Syllabus for $3^{\text {rd }}$ year students at I.E.S. Luis de Camoens. The ones with the same colour are mutually exclusive, so only one can be chosen.

\begin{tabular}{|c|c|}
\hline Subject & $\begin{array}{c}\text { Core (C), Optional (O) } \\
\text { or Free-Elective (F) }\end{array}$ \\
\hline English & C \\
\hline French & F \\
\hline Spanish (Supplementary) & F \\
\hline Mathematics (Supplementary) & C \\
\hline Biology and Geology & C \\
\hline Physical Education & C \\
\hline Visual Arts Education & C \\
\hline Physics and Chemistry & C \\
\hline Geography and History & C \\
\hline Spanish & C \\
\hline Technology & O \\
\hline Mathematics (Applied) & O \\
\hline Mathematics (Academical) & O \\
\hline Religion & O \\
\hline Ethics & \\
\hline
\end{tabular}

This group comprised 3 repeat students and 13 students with pending coursework subjects. All other third year groups at the school chose what we call Academical subjects, which lead to university studies. In this group, however, we could find students with Applied subjects, which are mainly focused on pursuing vocational studies.

In order to see the general performance of students, we approximate the seven key competencies [3] by using the final marks of the subjects in Table 1 combined as follows (Table 2):

Table 2. Combination of subjects for key competencies assignation.

\begin{tabular}{|c|c|}
\hline Key Competency & Subjects \\
\hline $\begin{array}{c}\mathrm{CL} \\
\text { (Communication) }\end{array}$ & $\begin{array}{l}\text { Spanish } \\
\text { English }\end{array}$ \\
\hline $\begin{array}{c}\text { CMCT } \\
\text { (Mathematical competence and } \\
\text { basic competences in science and } \\
\text { technology) }\end{array}$ & $\begin{array}{c}\text { Physics and Chemistry } \\
\text { Biology and Geology } \\
\text { Mathematics }\end{array}$ \\
\hline $\mathrm{CD}$ & Technology \\
\hline
\end{tabular}




\begin{tabular}{|c|c|}
\hline (Digital) & \\
\hline $\begin{array}{c}\text { CSC } \\
\text { (Social and civic competence) }\end{array}$ & $\begin{array}{c}\text { Religion } \\
\text { Ethics } \\
\text { Physical Education }\end{array}$ \\
\hline $\begin{array}{c}\text { SIEE } \\
\text { (Sense of initiative and } \\
\text { entrepreneurship) }\end{array}$ & $\begin{array}{c}\text { Visual Arts Education } \\
\text { Physical Education }\end{array}$ \\
\hline CEC & $\begin{array}{c}\text { Geography and History } \\
\text { Visual Arts Education }\end{array}$ \\
\hline (Cultural awareness and expression) & $\begin{array}{c}\text { Average of all other } \\
\text { competencies }\end{array}$ \\
\hline AA
\end{tabular}

The subjects grouped in Table 2 for each key competency are, as we understand, the ones more related to said competency. These choices are arguable, of course, and represent an approximation, to see, roughly, how students performed at the end of the school year. The averaged marks of the subjects in each key competency are then classified (Table 3):

Table 3. Correspondence between marks and levels for key competencies.

\begin{tabular}{|c|c|c|c|}
\hline 1 & 2 & 3 & 4 \\
\hline $0-3$ & $3-5$ & $5-7$ & $7-10$ \\
\hline
\end{tabular}

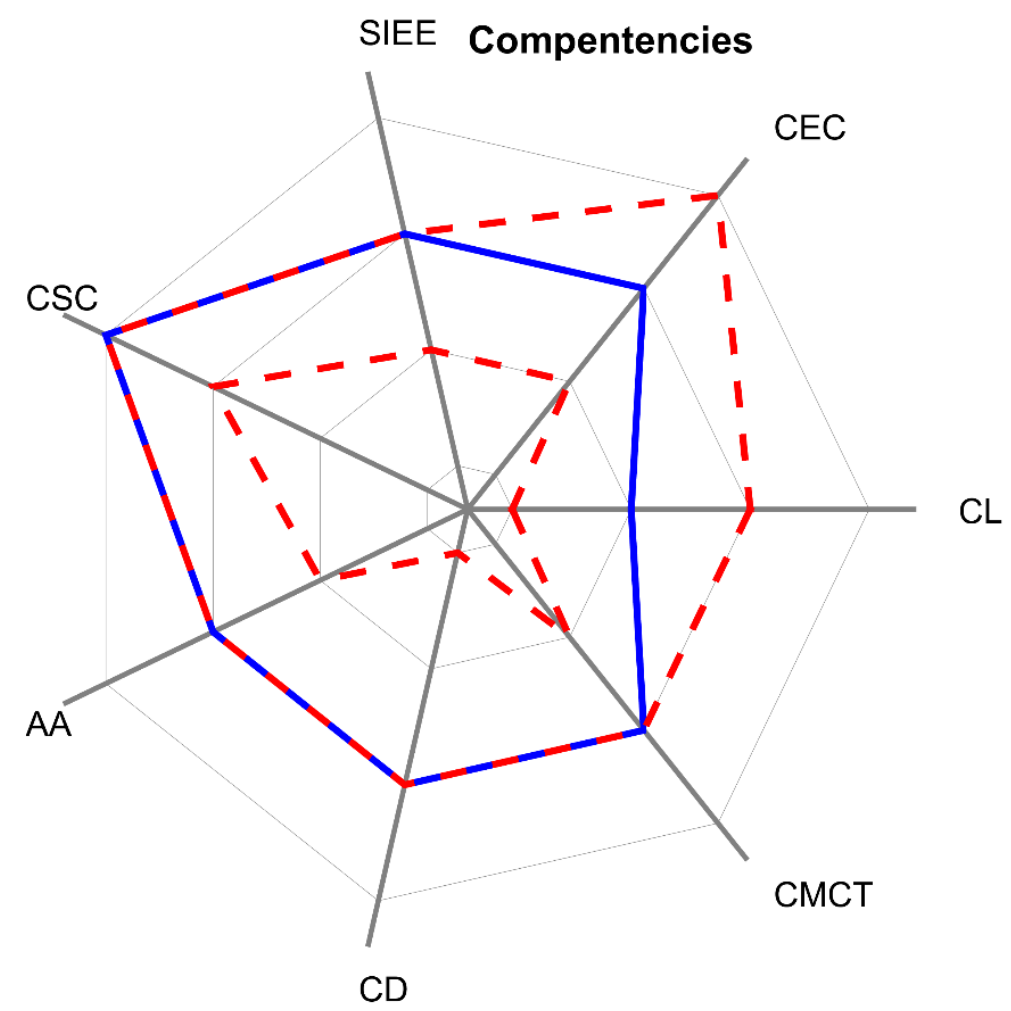

Figure 6. Median (in blue), first and third quartile (in red) of the key competencies for the students calculated as described in the text. Level 1 is in the centre and 4 in the outer circle. 
In Figure 6 we show the distribution of the final performance of the 24 students we used the VISLEDS method on. The first thing we notice is that the lowest score is achieved in the communication competency (CL), as would be expected in Ceuta [19]. We also note that most of students' marks lie around 5 (see correspondence in Table 3), which is the minimum mark to pass each subject.

We first performed a test in which students answered basic questions about the structure of the atom, already seen in $2^{\text {nd }}$ grade. In order to pass this test, they had to obtain a score of 5 over 10. This test is labelled as Initial Exam in Figure 5, and stablishes a baseline for the students' background knowledge on the topic.

For the remaining tests, we divided the questions into three parts: writing formulae, naming, and drawing of Lewis diagrams. We counted here the number of mistakes in each part. Note that in order to pass this topic in the syllabus, our students are required to obtain less than $1 / 3$ of mistakes in the overall test. Tests are usually made of 30 questions of naming/writing formulae. We introduced a variable number of questions in which students had to draw the Lewis diagrams. At the beginning, we introduced 10 questions, then we lowered the number up to 2 at the end of the learning process. Also, to see how dependent students were on the Lewis representation, the fifth test had no questions related to them.

Besides analysing the overall results, we also grouped data by the students' communication competency level (CL), their visual education's final marks (EPV), and their maths' final marks (MAT). We did not use the competencies as described in Table 2 because it is a rough approximation and our results could be hindered by that choice. We only chose the communication competency described there because it is pretty straightforward. The next section is dedicated to extracting conclusions from the data collected and grouped like this.

\section{Results}

In Table 4 we illustrate the main results of this study. An overall improvement of around $8 \%$ is found. In Figure 7 we show the evolution of the students' marks (probability of mistakes, actually) along the learning process. We notice that the first test with binary salts (Test 4), and the one with binary compounds and no Lewis representation questions (Test 6), have a median of mistakes above the allowed threshold. The first one implies an increase in the complexity of compounds. The second one, apart from the increase in the complexity of 
compounds, it can also imply that Lewis representation helps students to think about these particular tasks.

In Table 4 we also observe that the improvement is very noticeable for students with initial marks right below 5 . In general, students with lower initial marks improved, whereas students with higher marks in the initial test worsened their marks. This could be explained by the expertise reversal effect, in which learners with low prior knowledge improve when visual representation is used in the learning process [15], and learners with high prior knowledge experience an increased cognitive load which interferes with fluent execution of appropriate cognitive processes [38].

Table 4. Final results compared to the initial test. We compare the probability of surpassing between the initial and final tests. In blue, instances in which students' marks improved. In red, in which they worsened. In black, the proportion of students that surpassed the initial test and the last one is the same.

\begin{tabular}{|c|c|c|c|c|}
\hline Grouping & \# students & $\begin{array}{c}\text { Initial } \\
\text { probability of } \\
\text { passing the test }\end{array}$ & $\begin{array}{c}\text { Probability of } \\
<=1 / 3 \text { mistakes }\end{array}$ & Increment \\
\hline all & 24 & 0,58 & 0,67 & 8,33 \\
\hline \multicolumn{5}{|c|}{ Marks in the Initial test } \\
\hline $0-3(1)$ & 7 & 0,00 & 0,43 & 42,86 \\
\hline $3-5(2)$ & 3 & 0,00 & 1,00 & 100,00 \\
\hline $5-7(3)$ & 4 & 1,00 & 0,50 & $-50,00$ \\
\hline $7-10(4)$ & 10 & 1,00 & 0,80 & $-20,00$ \\
\hline \multicolumn{5}{|c|}{ Communication Competencies } \\
\hline CL1 & 9 & 0,22 & 0,44 & 22,22 \\
\hline CL2 & 7 & 0,71 & 0,71 & 0,00 \\
\hline CL3 & 8 & 0,88 & 0,88 & 0,00 \\
\hline \multicolumn{5}{|c|}{ Final Marks in Visual Education } \\
\hline $5-7(3)$ & 8 & 0,63 & 0,63 & 0,00 \\
\hline $7-10(4)$ & 16 & 0,56 & 0,69 & 12,50 \\
\hline \multicolumn{5}{|c|}{ Final Marks in Mathematics } \\
\hline All 0-3 (1) & 4 & 0,00 & 0,50 & 50,00 \\
\hline All 3-5 (2) & 4 & 1,00 & 0,50 & $-50,00$ \\
\hline All 5-7 (3) & 10 & 0,90 & 0,80 & $-10,00$ \\
\hline All 7-10 (4) & 6 & 0,17 & 0,67 & 50,00 \\
\hline Applied 0-5 (1-2) & 4 & 0,00 & 0,50 & 50,00 \\
\hline Applied 5-10 (3-4) & 5 & 0,00 & 0,60 & 60,00 \\
\hline Academic $0-5(1-2)$ & 4 & 1,00 & 0,50 & $-50,00$ \\
\hline Academic 5-10 (3-4) & 11 & 0,91 & 0,82 & $-9,09$ \\
\hline
\end{tabular}




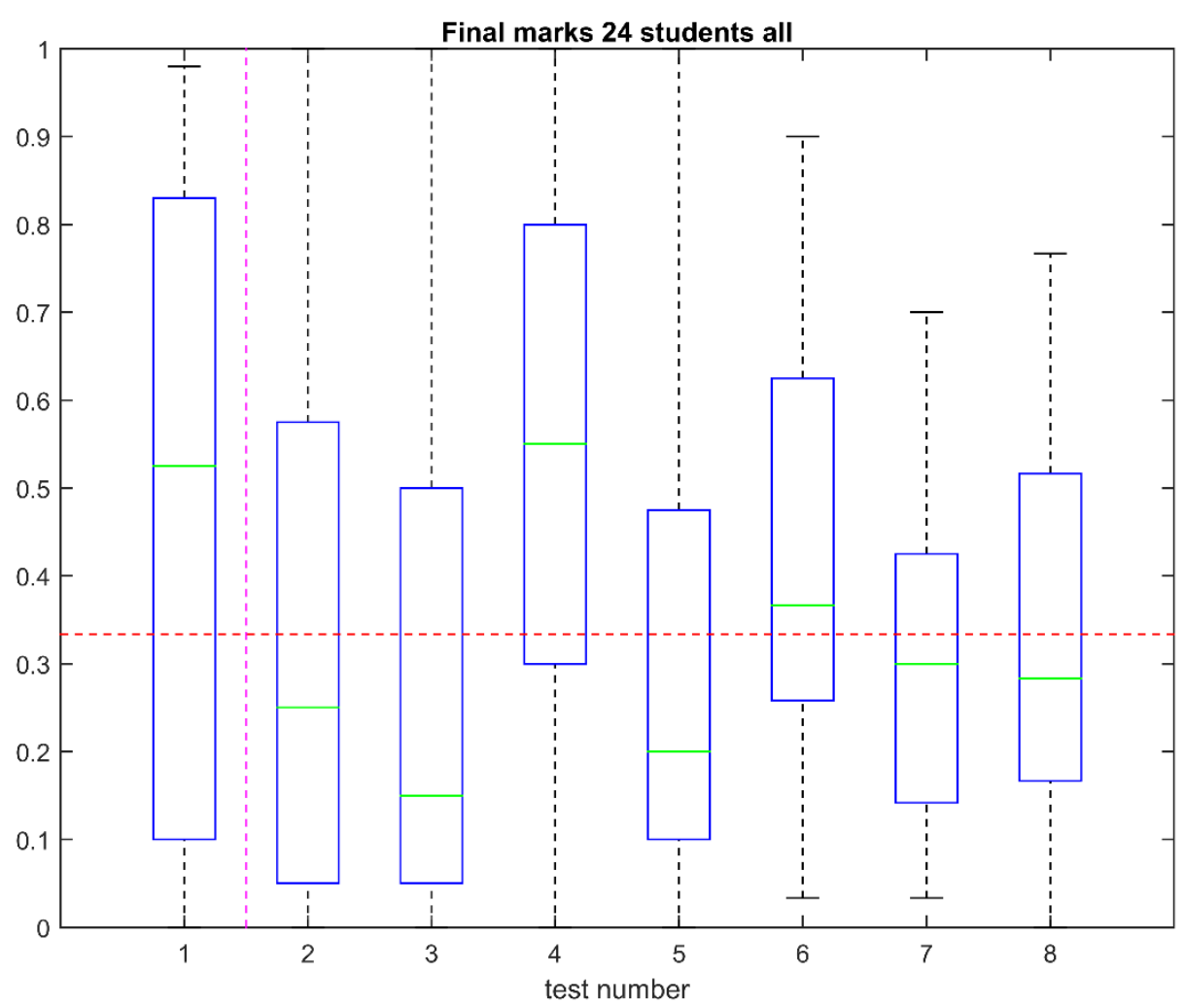

Figure 7. Box plots for the students' marks for all tests. Test 1 is the Initial Exam, and is scaled so its mark goes from 0 to 1 . Scores higher than 0.5 passed the test. For the remaining tests, we draw the probability of mistakes. In green, the median. The blue box delimits the interval Q1-Q3 of the distribution. The horizontal red line signals the 1/3 threshold.

Figure 8 shows the box plots when we divide students into groups related to their initial exam's marks. The first two groups only had room for improvement, if we realise, they failed the initial tests. The other two groups only had the possibility of maintaining their status or failing, obviously. So, the interesting part of this graph is that all students that nearly failed (3-5 in the initial exam), passed the final test in this part of the curriculum, and that the bulk of best students (7-10 in the initial test) maintained their grades. Note also that intermediate students (5-7 in the initial exam) had initial grades very close to failing (1/2). Since prior knowledge about this topic seems not to be very predictive about the acquisition of this skill, we will thus investigate which competencies are the most relevant ones for students to take advantage of this method. 

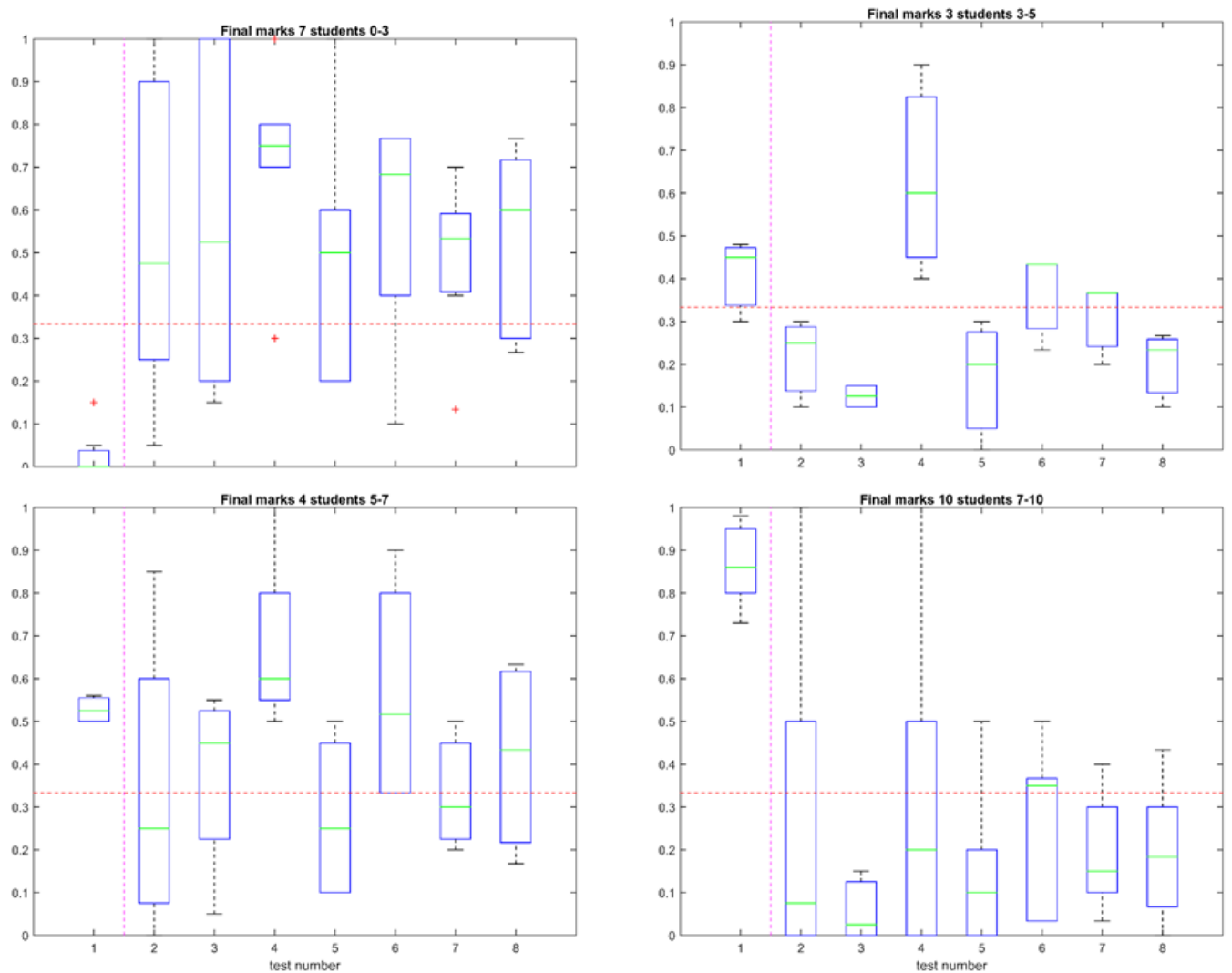

Figure 8. Box plots as described in Figure 7 by grouping students by their initial exam's marks.

In Table 4 we observe two important results: first, students with the lowest scores in the communication competency improved but, most importantly, students with higher scores were not adversely affected by this method, on average. The second important result is that, also on average, students with higher marks in visual arts education improved and, again, the ones with lower marks were not negatively affected.

We now understand the results depicted in Figure 8. The visual representation of inorganic formulation decreases the extraneous cognitive load [14] of students with low scores in communication competency but high scores in visual arts, whereas some students, even if they passed the initial exam, had a low score in communication competency but also a low score in visual arts. Their prior knowledge on the topic was most likely based on mnemonics. Even if the tasks were visually presented, the cognitive load was still high, because they had to make sense of two different encodings, visual and linguistic [38]. As already stated, this is not surprising, both in general observations [18], and in the particular case of Ceuta [19].

We now analyse our results with regard to the mathematical skills of each student. Note that we have two groups of data that do not overlap: students who studied Academical (MAC) 
and students who studied Applied Maths (MAP). If we mix all together and see the overall final marks, we notice that both the lowest and highest scores improved from their baseline marks, and went from failing the initial exam to passing the last one, and the intermediate groups worsened, on average, their results (Table 4). Now, if we focus on each group separately, we can see that students who chose Applied Maths instead of Academical improved, whereas the ones who chose the other option lowered their scores. In Figure 9 we illustrate these results. We clearly can see that our findings only reflect the fact that students in Applied Maths obtained lower scores in the initial exam, so there is much room for improvement. Therefore, a similar effect to the one observed in Figure 8 is found here. Actually, the division between low and high scores in the initial test is very noticeable here. Students who intended to attend university (Academical option), possessed a higher baseline level of knowledge than the ones who aspired to vocational studies (Applied option).
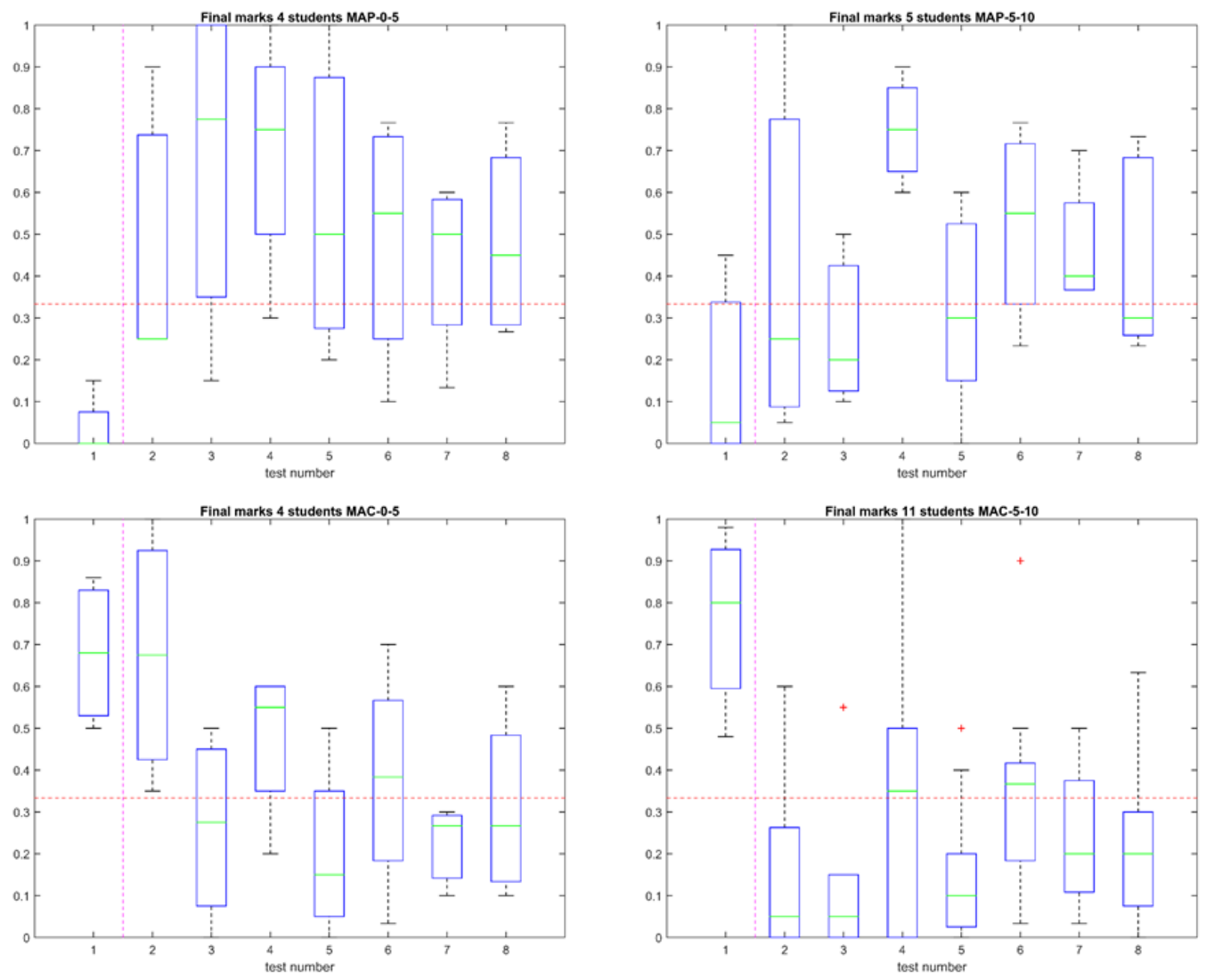

Figure 9. Box plots as described in Figure 7 by grouping students by their math's marks. We also divided them between Applied (MAP) and Academical (MAC). 
So far we analysed the data referring to the method in general. Now we now will try to understand how (if) the Lewis dot representation method (VISLEDS) is related to the way students apprehend the information. In Figure 10 we show how the probability of mistakes evolves over time through all tests, now detailing each different kind of questions. When asked for formulae, students are presented with a name, and when naming, the opposite goal is asked. For Lewis dot structure questions, we choose either a name or a formula from the other questions, and ask them to draw the Lewis representation. It is thus a way for them thinking about the way elements are bonded in those compounds.
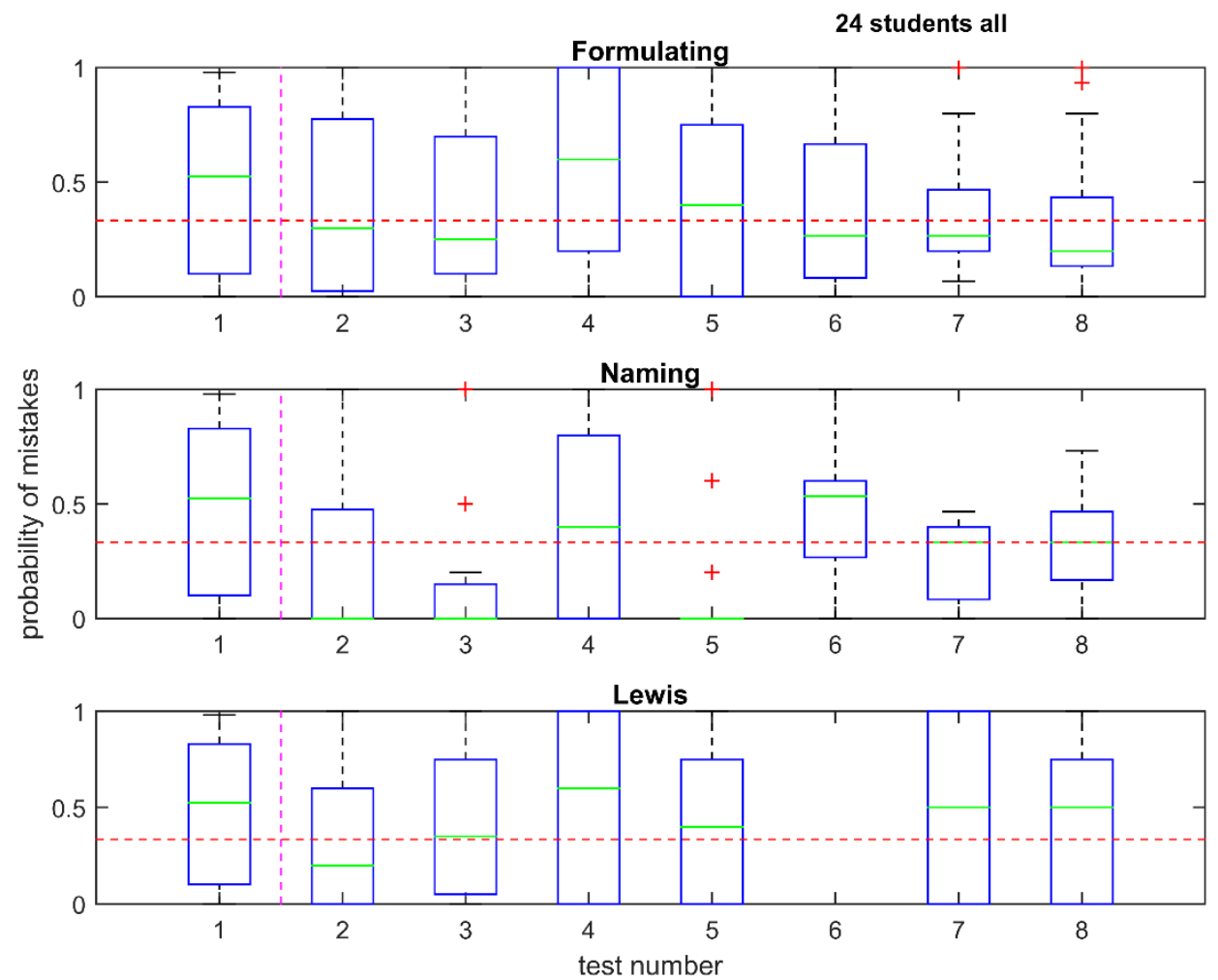

Figure 10. Box plots for the different kind of questions. We also plot the initial exam as reference, as in Figure 7. Note that Test 6 has not Lewis dot representation questions.

In general, we see that, when a high probability of mistakes in the Lewis representation is found in the tests, a high probability of mistakes in the other kind of questions is found too. However, it is very difficult to visually discern the correlation between these variables. We thus proceed to calculate the correlations, both linear [30] and nonlinear [31], between scores in the Lewis questions and the other two kind of questions. We also calculate correlations with the final marks, accounting for both, naming and writing formulae questions together. In Table 5 we find a summary of our results. 
The first thing we realise is that there is a positive correlation between the ability to draw the Lewis representation of the compounds and the ability to name and write the formulae of those same compounds. In general, $52 \%$ of results can be explained by a linear correlation when writing the formula, and $44 \%$ when naming. $57 \%$ of final scores can be explained by a linear correlation with the ability to draw the Lewis diagram.

Table 5. Correlation between scores in the Lewis representation questions and the naming and writing formulae questions. In blue, higher score between writing formulae and naming. In bold, those instances in which the overall mark has a higher correlation than the individual components of the questions. Mutual information is given in bits.

\begin{tabular}{|c|c|c|c|c|c|c|c|}
\hline Group & $\begin{array}{c}\# \\
\text { students }\end{array}$ & $\begin{array}{c}\text { Correlation } \\
\text { formulation }\end{array}$ & $\begin{array}{c}\text { Correlation } \\
\text { naming }\end{array}$ & $\begin{array}{c}\text { Correlation } \\
\text { total }\end{array}$ & $\begin{array}{c}\text { Mutual } \\
\text { information } \\
\text { formulation }\end{array}$ & $\begin{array}{c}\text { Mutual } \\
\text { information } \\
\text { naming }\end{array}$ & $\begin{array}{c}\text { Mutual } \\
\text { information } \\
\text { total }\end{array}$ \\
\hline All & 24 & 0.52 & 0.44 & $\mathbf{0 . 5 7}$ & 0.62 & 0.48 & $\mathbf{0 . 7 5}$ \\
\hline $0-3$ & 7 & 0.20 & 0.33 & 0.31 & 1.71 & 1.35 & 1.29 \\
\hline $3-5$ & 3 & 0.40 & 0.34 & $\mathbf{0 . 4 5}$ & 0.92 & 1.07 & $\mathbf{1 . 4 9}$ \\
\hline $5-7$ & 4 & 0.41 & 0.10 & 0.32 & 1.71 & 1.01 & $\mathbf{1 . 8 6}$ \\
\hline 7-10 & 10 & 0.33 & 0.50 & $\mathbf{0 . 5 3}$ & 0.64 & 0.34 & $\mathbf{0 . 6 6}$ \\
\hline CL1 & 9 & 0.28 & 0.26 & $\mathbf{0 . 3 2}$ & 1.27 & 1.18 & 1.17 \\
\hline CL2 & 7 & 0.41 & 0.36 & $\mathbf{0 . 5 2}$ & 0.72 & 0.70 & $\mathbf{1 . 2 2}$ \\
\hline CL3 & 8 & 0.42 & 0.37 & $\mathbf{0 . 4 7}$ & 0.56 & 0.39 & $\mathbf{0 . 9 0}$ \\
\hline EPV-5-7 & 8 & 0.74 & 0.53 & 0.71 & 1.53 & 0.89 & 1.41 \\
\hline EPV-7-10 & 16 & 0.41 & 0.39 & $\mathbf{0 . 4 9}$ & 0.52 & 0.50 & $\mathbf{0 . 8 9}$ \\
\hline MAT-0-3 & 4 & 0.24 & 0.33 & $\mathbf{0 . 3 3}$ & 1.40 & 1.18 & $\mathbf{1 . 9 4}$ \\
\hline MAT-3-5 & 4 & 0.43 & 0.30 & $\mathbf{0 . 4 7}$ & 1.11 & 1.39 & 1.15 \\
\hline MAT-5-7 & 10 & 0.33 & 0.31 & $\mathbf{0 . 4 0}$ & 0.53 & 0.33 & $\mathbf{0 . 8 3}$ \\
\hline MAT-7-10 & 6 & 0.59 & 0.50 & $\mathbf{0 . 6 4}$ & 1.33 & 1.06 & $\mathbf{1 . 4 7}$ \\
\hline MAC-0-5 & 4 & 0.43 & 0.30 & $\mathbf{0 . 4 7}$ & 1.11 & 1.39 & 1.15 \\
\hline MAC-5-10 & 11 & 0.35 & 0.34 & $\mathbf{0 . 4 3}$ & 0.51 & 0.33 & $\mathbf{0 . 8 0}$ \\
\hline MAP-0-5 & 4 & 0.24 & 0.33 & $\mathbf{0 . 3 3}$ & 1.40 & 1.18 & $\mathbf{1 . 9 4}$ \\
\hline MAP-5-10 & 5 & 0.45 & 0.33 & $\mathbf{0 . 4 8}$ & 1.66 & 1.58 & 1.60 \\
\hline
\end{tabular}

Another important result is that, in general, the Lewis dot structure correlates in a higher proportion with questions concerning writing formulae (Figure 11). This is not surprising, since the Lewis structure reflects how many elements form the chemical compound (Figure 3). However, when naming the compound, a higher cognitive load is added for retaining the rules used by the IUPAC [39]. Finally, the combination of writing formulae and naming 
questions would have a richer structure in the probability distribution. Thus the higher mutual information.

We find a roughly negative trend between the mutual information and the probability of passing the final test (Figure 11). Since the more mistakes the less probability of passing, this result is in agreement with the ones found for the linear correlations. We note that the structure of mistakes (mutual information) is richer for students that do not pass the exam. They seem to experience a higher extraneous load of information, so less working memory capacity remains for dealing with the intrinsic cognitive load, in terms of Cognitive Load Theory [13]. We notice an exception to that rule: for the group with a $100 \%$ of probability of passing the test, the mutual information is high, compared to those with $80-90 \%$ of probability. In Table 4 we see that it corresponds to the group of students with an score 3-5 in the initial exam. We observe in Figure 8 they are close to passing Test 1. It means they decided to make the effort to learn this topic, even if the cognitive load was high.

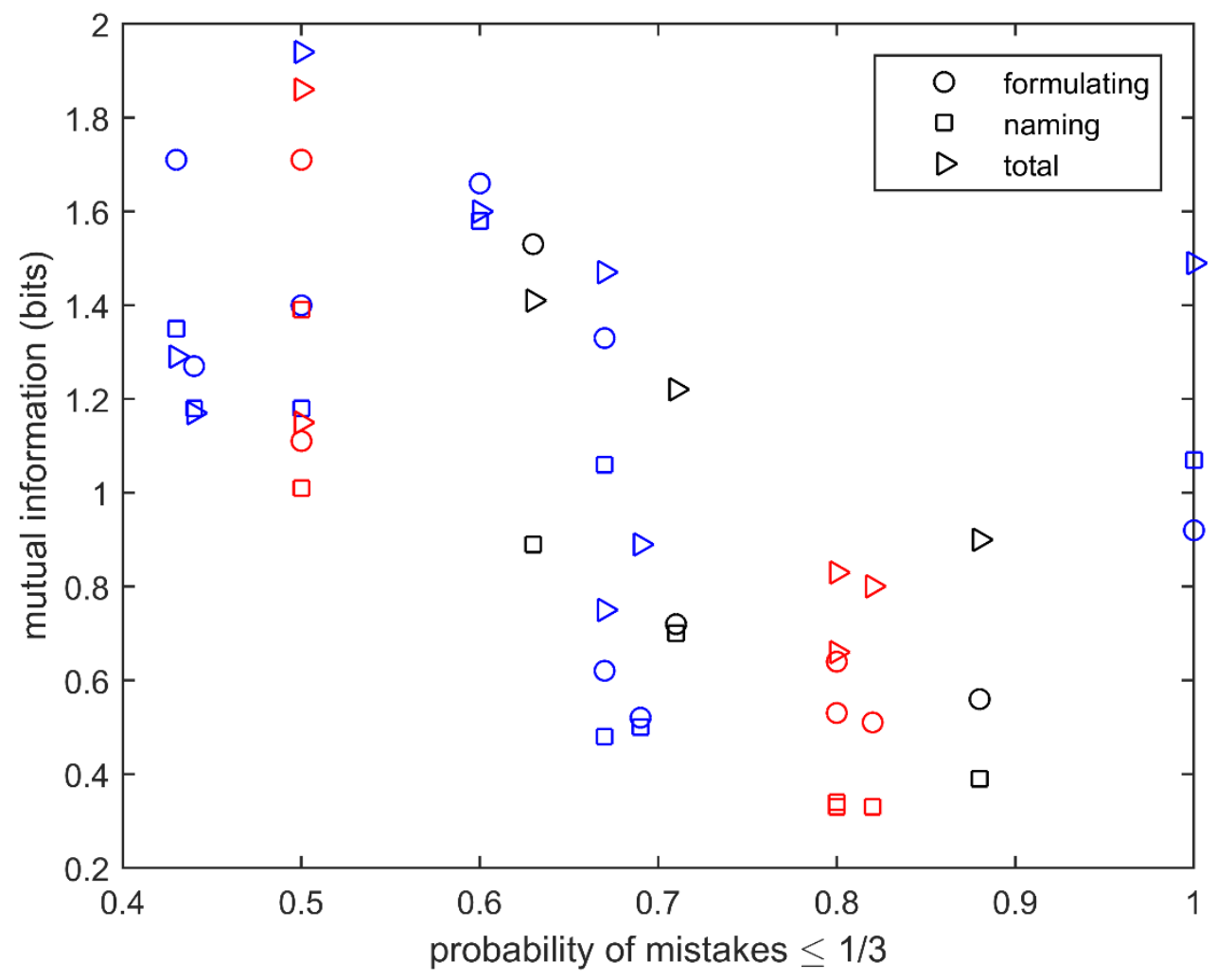

Figure 11. Probability of students with mistakes lower than $1 / 3$ (probability of passing the test) vs. mutual information. In blue, subgroups that improve. In red, subgroups that worsen. In black, subgroups that stay the same. 
We are particularly interested in the information content when focusing only on the communication competency or visual arts education. While with the other classifications visual representation might not highly correlate with writing formulae questions, those two classifications stand out for showing higher correlations in those kind of questions, both linear and nonlinear (Figure 12). Moreover, in those cases we find that the lowest scores in those competencies are related to a lower mutual information in the final result than for questions related to writing formulae only. We actually observe a decrease of mutual information with increasing competency in both cases. So, again, these two competencies, communicative and visual, are the ones that might predict the cognitive load that the method is requiring from students. Following on this, we can see that students with lower visual skills experience a higher extraneous load of information. The other classifications seem to present a mixture of learning styles [17].

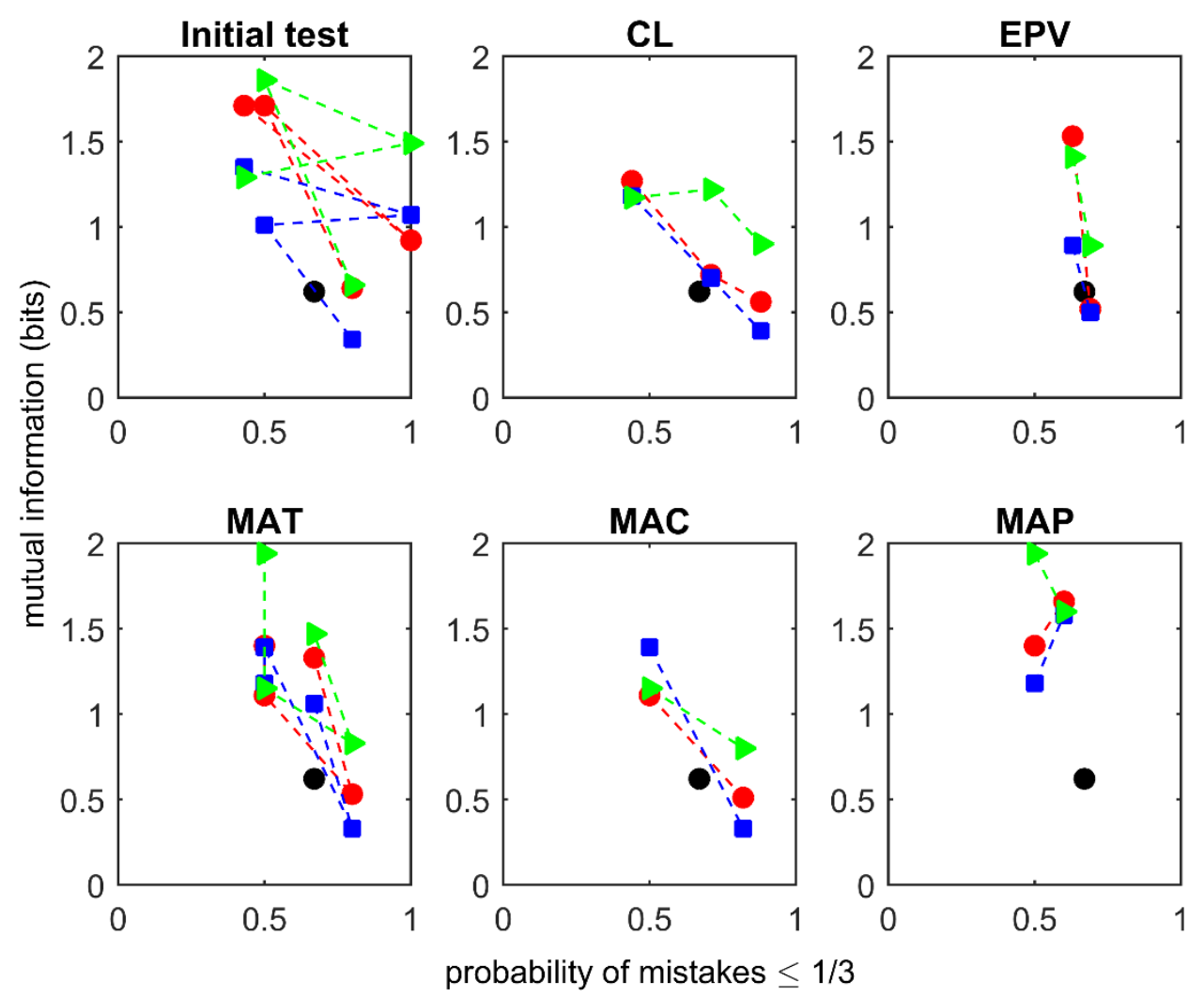

Figure 12. Probability of students with mistakes lower than $1 / 3$ (probability of passing the test) vs. mutual information for each grouping. The black dot represents the overall result.

\section{Discussion}

Lewis dot structures have been around for a century now [20]. It appeared as a new representation that helped chemists to deeper understanding the polar/non-polar properties 
of molecules and thus forecasting their reactive behaviour. They are introduced for representing the bonds in a molecule. However, it has not been used, to our knowledge, to introduce students in chemistry formulation for the first time as a way to facilitate students' learning process. They are used when students already had prior knowledge based on mnemonic's rules. Lewis dot structures are taught as a set of rules too, and not for developing the students' representational competence [21,22]. Actually, one of the main problems for students to going on with chemistry in higher levels is their low representational competency, the capacity to form an image of the molecular structure and thus being able to forecast some of the compounds' properties.

The VISLEDS method, however, capitalises from the advantage of presenting information in a more compact way [15], and overcomes one of the main problems found when teaching chemistry, which is the insufficient communication competencies of students when facing these tasks [18]. Our results show that this method has been proven to be effective in doing just that. It strengthens the link between sub-micro and symbolic [11] representation of chemical bonds.

Of course, this is not the only ingredient in the method. We gradually increased the complexity of tasks [13], from simple compounds to more complex ones, and from elements with only one oxidation number to other with multiple numbers. We also checked constantly the learning process by means of tests, to enhance retention [28]. In Figure 7 we observe an improvement from tests 6 to 7 (both about the whole range of different compounds to be learned). Test 8 also required from students to memorise oxidation numbers. So, that could be the cause of the slightly worse results found.

One of the main findings is how we can classify students learning process. The classifications based on communication and visual skills worked, but other attempts, such as grouping them by their mathematical competencies, do not worked. This is understandable for novice learners in maths, as $3^{\text {rd }}$ grade high school students are, because language and visual perception are more basic cognitive abilities than mathematics [40, 41]. Moreover, the development of reading skills may depend to a certain extent on the development of basic visual perception [42]. This is also reflected in the higher correlation of mistakes found for students with lower marks on visual arts education (see data for mutual information in Table $5)$. 
Students to whom representation (any kind, visual, linguistic or mathematical) comes easily, the structure of errors is poor, so that their distribution is narrow. Entropy (information), tends to low values. They have less mistakes, so they have learned the topic and the translation from formulae to identification of compounds and Lewis structure is a tautology. Tautologies (no errors), as well as contradictions (all errors), have cero entropy [16, 23]. So, their mistakes inform us that their cognitive effort is low (

Table 6, Figure 13). This also is linked with the constructivist theories, in which learners correlate what they know or they are able to do with what they need to learn [8].

Table 6. Entropy of the probability distributions of mistakes. In bold, the highest values in each classification.

\begin{tabular}{|c|c|c|c|c|c|}
\hline Group & \# students & Entropy Lewis & $\begin{array}{c}\text { Entropy } \\
\text { Formulating }\end{array}$ & $\begin{array}{c}\text { Entropy } \\
\text { naming }\end{array}$ & Entropy total \\
\hline All & 24 & 2.29 & 2.84 & 2.50 & 3.10 \\
\hline $0-3$ & 7 & $\mathbf{2 . 4 7}$ & $\mathbf{3 . 1 5}$ & 2.41 & 2.79 \\
\hline $3-5$ & 3 & 1.64 & 2.38 & 2.84 & 2.78 \\
\hline $5-7$ & 4 & 2.29 & 2.94 & 2.45 & $\mathbf{3 . 0 1}$ \\
\hline $7-10$ & 10 & 1.72 & 1.93 & 1.79 & 2.30 \\
\hline CL1 & 9 & $\mathbf{2 . 5 2}$ & $\mathbf{3 . 1 2}$ & 2.55 & 2.96 \\
\hline CL2 & 7 & 2.00 & 2.36 & 2.57 & $\mathbf{3 . 0 6}$ \\
\hline CL3 & 8 & 1.58 & 2.35 & 1.79 & 2.36 \\
\hline EPV-5-7 & 8 & 2.20 & $\mathbf{3 . 0 2}$ & 2.47 & 2.85 \\
\hline EPV-7-10 & 16 & $\mathbf{2 . 2 9}$ & 2.68 & 2.42 & $\mathbf{3 . 1 3}$ \\
\hline MAT-0-3 & 4 & 1.97 & $\mathbf{3 . 1 5}$ & 2.40 & 2.85 \\
\hline MAT-3-5 & 4 & 2.04 & 2.50 & 2.43 & 2.93 \\
\hline MAT-5-7 & 10 & 1.86 & 2.61 & 1.88 & 2.72 \\
\hline MAT-7-10 & 6 & $\mathbf{2 . 4 2}$ & 2.35 & 2.54 & 2.94 \\
\hline MAC-0-5 & 4 & 2.04 & 2.50 & 2.43 & 2.93 \\
\hline MAC-5-10 & 11 & 1.78 & 2.52 & 1.79 & 2.61 \\
\hline MAP-0-5 & 4 & 1.97 & $\mathbf{3 . 1 5}$ & 2.40 & 2.85 \\
\hline MAP-5-10 & 5 & $\mathbf{2 . 5 5}$ & 2.40 & 2.66 & $\mathbf{2 . 9 3}$ \\
\hline
\end{tabular}

Since the early beginnings of Cognitive Load Theory, a main question has arisen about how we can measure cognitive working load $[12,13]$. It can be done by indirect measures such as time to perform the tasks or performance accuracy, dual-tasks performance measures, or biomeasures [13]. Sweller, in his seminal work [12], introduced cognitive load in an algorithmic fashion, as steps needed to reach the goal. Here, we propose to use Information Theory [23, 24] measures to do just that. Cognitive Load Theory is certainly inspired on it, since our brain would work as the channel that processes the message. 
In particular, we can correlate cognitive working load with the information contained in the probability distribution of the mistakes students make. We can also estimate the extraneous load as long as we introduce questions which correlate mistakes with the particular way we present the tasks.

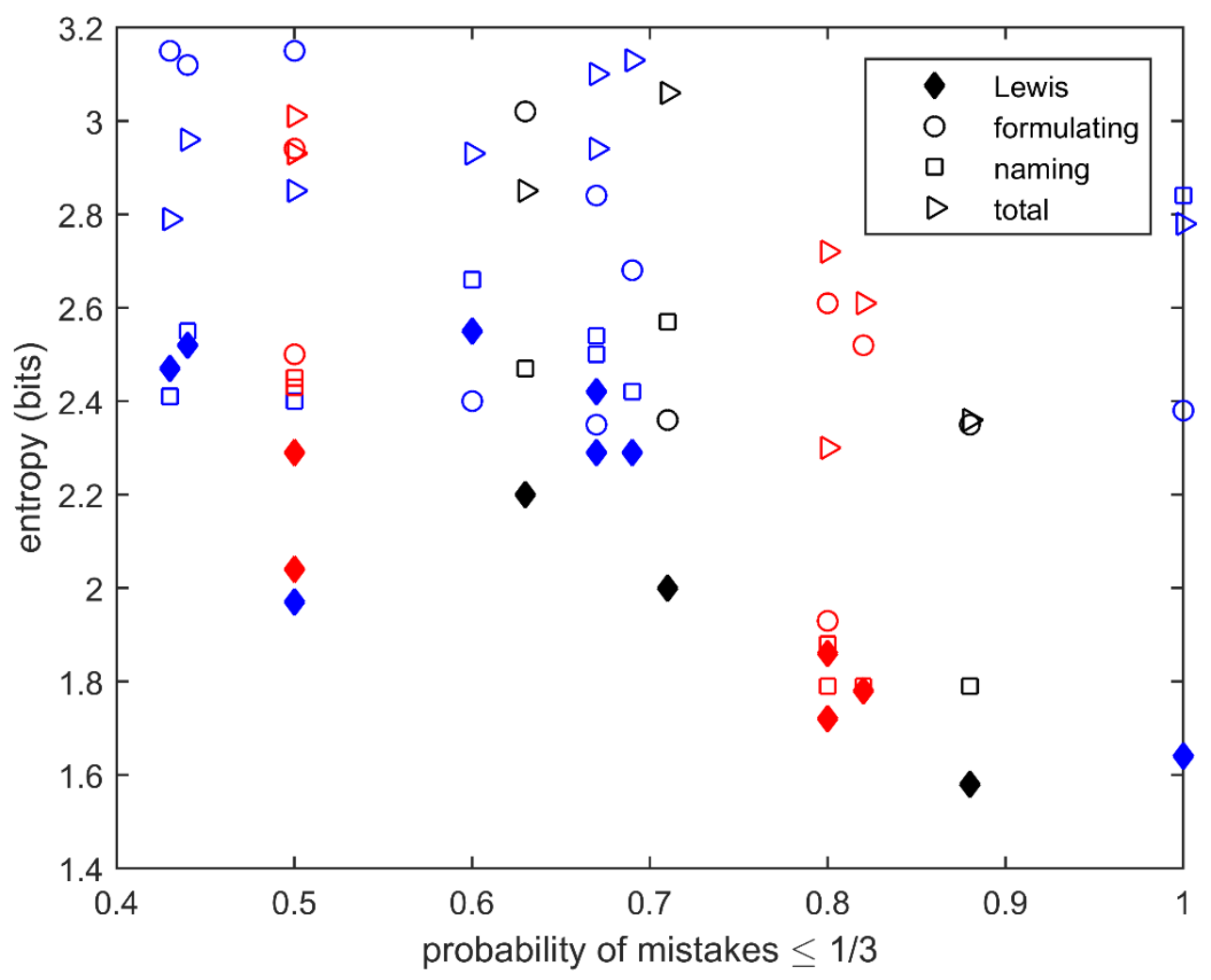

Figure 13. Probability of students with mistakes lower than $1 / 3$ (probability of passing the test) vs. entropy. In blue, subgroups that improve. In red, subgroups that worsen. In black, subgroups that stay the same.

\section{Conclusions}

In summary, we have presented a new method (VISLEDS) that introduces novice students to chemistry formulation based on the visual representation given by the Lewis dot structures [20], in opposition of those based on mnemonics. We do not use Lewis dot structures as a learning goal, but as a means to an end, as opposed to the way Lewis dot structures are usually taught $[21,22]$.

We have shown that this method improves the overall performance of the student's group. Particularly, for students with low communicative competencies but high visual perception skills. Moreover, it does not worsen the performance of students with high communicative competencies and/or low visual perception skills. Mathematical competencies are found not 
to be good predictors of how these students learn. Surely, because it requires a higher level of expertise in symbolic representation than the one supposed for $3^{\text {rd }}$ year high school students. Therefore, communicative and artistic competencies should be exploited and/or encouraged in this particular topic and level.

Finally, we have shown how cognitive working load can be measured by using the probability distribution of mistakes and Information Theory basic measures. Moreover, if we design questions that correlate the way information is presented with students' mistakes, we can approximate the extraneous cognitive load.

\section{Acknowledgements}

Thanks to all teachers in I.E.S. Luis de Camoens for their useful tips and help. Thanks to Jezabel Jiménez Lloret for her comments and critical review of the manuscript.

\section{References}

[1] P. Chields and M. Sheehan, "What's diicult about chemistry? An Irish perspective," Chemistry Education Research and Practice, vol. 10, pp. 204-218, 2009.

[2] BOE, Orden ECD/65/2015, de 21 de enero, , por la que se describen las relaciones entre las competencias, los contenidos y los criterios de evaluación..., 2015.

[3] OCDE, "Definición y selección de competencias (DeSeCo)," 2003.

[4] J. Piaget and E. Duckworth, "Genetic Epistemology," Am. Behav. Sci., vol. 13, p. 459-480, 1970.

[5] L. S. Vygotsky, Mind in Society: The Development of Higher, Cambridge: Harvard University Press , 1978.

[6] D. P. Ausubel, The Psychology of Meaningful Verbal Learning, New York: Grune \& Stratton, 1963.

[7] J. D. Novak, D. B. Gowin and J. B. Kahle, Learning How to Learn, Cambridge: Cambridge University Press, 1984. 
[8] M. M. Cooper and R. L. Stowe, "Chemistry Education Research-From Personal Empiricism to Evidence, Theory, and Informed Practice," Chemical Reviews, vol. 118, no. 12, pp. 6053-6087, 2018.

[9] IanH, "https://teachingofscience.wordpress.com/2017/02/15/energy-languagethoughts-part-2/,” 2020. [Online].

[10] The National Research Council, "How People Learn: Brain, Mind, Experience, and School: Expanded ed.," National Academies Press, Washington, DC, 2000.

[11] A. H. Johnstone, "Macro- and Microchemistry," Sch. Sci. Rev., vol. 64, p. 377-379, 1982.

[12] J. Sweller, "Cognitive Load During Problem Solving: Effects on Learning," Cognitive Science, vol. 12, pp. 257-285, 1988.

[13] J. Leppink and A. Heuvel, "The evolution of cognitive load theory and its application to medical education.," Perspectives on medical education, vol. 4, no. 3, pp. 119-127, 2015.

[14] J. Sweller, "Cognitive load theory, learning difficulty, and instructional design," Learn Instr., vol. 4, p. 295-312, 1994.

[15] J. H. Larkin and H. A. Simon, "Why a diagram is (sometimes) worth ten thousand words," Cognitive Science, vol. 11, pp. 65-99, 1987.

[16] L. Wittgenstein, Tractatus logico-philosophicus, Alianza Editorial (4ª Reimpresión, 2016), 1922.

[17] Y. Li, J. Medwell, D. Wray, L. Wang and X. Liu, "Learning Styles: A Review of Validity and Usefulness," Journal of education and training studies, no. 4, pp. 90-94, 2016.

[18] R. Kempa, “Students' learning diiculties in science, Causes and possible remedies," Enseñanza de las Ciencias, vol. 9, no. 2, pp. 119-128, 1991.

[19] S. (. Sánchez, ¿Por qué dejé de estudiar? EL ABANDONO ESCOLAR TEMPRANO EN CEUTA Y MELILLA, Granada: Universidad de Granada, 2013.

[20] G. N. Lewis, "The Atom and the Molecule," J. Am. Chem. Soc., vol. 38, no. 4, p. 762$785,1916$. 
[21] B. B. Miburo, "Simplified Lewis Structure Drawing for Non-science Majors," J. Chem. Educ., vol. 75, no. 3, p. 317, 1993.

[22] S. Sandi-Urena, G. Loría Cambronero and D. Jinesta Chaves, "Conceptualisation of Lewis structures by chemistry majors," Chemistry Teacher International, 2019.

[23] C. Shannon, "A Mathematical Theory of Communication," Bell System Technical Journal, vol. 7, p. 379-423 \& 623-656, 1948.

[24] E. T. Jaynes, "Information Theory and Statistical Mechanics," Phys. Rev., vol. 106, no. 4, p. 620, 1957.

[25] BOE, Orden ECD/1361/2015, de 3 de julio, por la que se establece el currículo de Educación Secundaria Obligatoria y Bacbillerato para el ámbito de gestión MEC, 2015.

[26] E. Rutherford, "The Scattering of $\alpha$ and $\beta$ Particles by Matter and the Structure of the Atom," Philosophical Magazine, Vols. Series 6, vol. 21, pp. 669-688, 1911.

[27] M. Nückles, J. Roelle, I. Glogger-Frey, J. Waldeyer and A. Renkl, "The Self-RegulationView in Writing-to-Learn: Using Journal Writing to Optimize Cognitive Load in SelfRegulated Learning," Educational Psychology Review, 2020.

[28] J. D. Karpicke and W. R. Aue, "The testing effect is alive and well with complex materials," Educ. Psychol. Rev., vol. 27, p. 317-326, 2015.

[29] BOE, Ley Orgánica 8/2013, de 9 de diciembre, para la Mejora de la Calidad Educativa., 2013.

[30] K. Pearson, "Notes on regression and inheritance in the case of two parents," Proceedings of the Royal Society of London, vol. 58, p. 240-242, 1895.

[31] T. Cover and J. Thomas, Elements of Information Theory, New York: Wiley and Sons, 1991.

[32] K. W. Church and P. Hanks, "Word association norms, mutual information, and lexicography," Computational Linguistics, vol. 16, no. 1, pp. 22-29, 1990.

[33] J. P. Pluim, J. A. Maintz and M. A. Viergever, "Mutual-information-based registration of medical images: a survey," IEEE Transactions on Medical Imaging, vol. 22, no. 8, p. 9861004, 2003. 
[34] A. Jiménez, "Information theory approach to the Landers aftershock sequence," EPL, vol. 111, no. 1, p. 19001, 2015.

[35] G. Jensen, R. D. Ward and P. D. Balsam, "Information: theory, brain, and behavior," Journal of the experimental analysis of behavior, vol. 100, no. 3, p. 408-431, 2013.

[36] C. J. Cellucci, A. M. Albano and P. E. Rapp, "Statistical validation of mutual information calculations: Comparison of alternative numerical algorithms," Phys. Rev. E, p. 066208, 2005.

[37] A. Segura-Robles and M. E. Parra-González, “Analysis of Teachers’ Intercultural Sensitivity Levels in Multicultural Contexts,” Suistainability, vol. 11, p. 3137, 2019.

[38] S. Kalyuga, "Effects of Learner Prior Knowledge and Working Memory Limitations on Multimedia Learning," Procedia - Social and Behavioral Sciences, vol. 83, pp. 25-29, 2013.

[39] IUPAC, "IUPAC: International Union of Pure and Applied Chemistry," 2020. [Online]. Available: https://iupac.org/.

[40] J. Cui, Y. Zhang, D. Cheng, D. Li and X. Zhou, "Visual Form Perception Can Be a Cognitive Correlate of Lower Level Math Categories for Teenagers," Frontiers in Psychology, vol. 8, p. 1336, 2017.

[41] M. Meiers and J. Trevitt, "Language in the mathematics classroom," The Digest, NSWIT, 2010.

[42] X. Meng, A. Cheng-Lai, B. Zeng, J. Stein and X. Zhou, "Dynamic visual perception and reading development in Chinese school children," Ann Dyslexia., vol. 61, no. 2, pp. 161-176, 2011. 